\author{
Czesław MIEDZIAŁOWSKI ${ }^{1}$ \\ Michał BASZEŃ ${ }^{2}$ \\ Marta KOSIOR-KAZBERUK ${ }^{3}$ \\ Anna ŻAKOWICZ ${ }^{4}$ \\ Tadeusz CHYŻY ${ }^{5}$ \\ Damian SIWIK ${ }^{6}$
}

\title{
STAN NIEUKOŃCZONEJ KONSTRUKCJI BUDYNKU OWT PO 25 LATACH OD REALIZACJI I PROPOZYCJA SPOSOBU ANALIZY STATYCZNEJ
}

\begin{abstract}
Praca dotyczy stanu technicznego nieukończonej konstrukcji systemowego budynku OWT po 25 latach od realizacji. Przedstawiono stan wykonania tego obiektu oraz jakość robót, głównie w zakresie połączeń pod względem geometrii i odniesienia do wymagań katalogowych tego systemu. Pokazano stan połączeń ścian szczytowych ze ścianą podłużną oraz połączeń ścian zewnętrznych (tzw. belkościan) ze ścianami poprzecznymi. Podano informacje co do stanu betonu i stali w konstrukcji tzn. w elementach i w złączach. Wskazano miejsca szczególnie zdegradowane i zagrożone korozją . Stwierdzono w trakcie analiz wbudowanie wadliwych prefabrykatów w zakresie geometrii i cech materiałowych oraz niewłaściwy montaż. Podano również efektywny sposób do analizy statycznej konstrukcji budynku w modelu trójwymiarowym, z uwzględnieniem podłoża gruntowego, wadliwego montażu i dodatkowych oddziaływań na konstrukcję. W podsumowaniu podano główne stwierdzone wady w omawianym budynku, które mogą stanowić zagrożenie bezpieczeństwa konstrukcji.
\end{abstract}

Słowa kluczowe: budynki wielkopłytowe, prefabrykaty, połączenia, bezpieczeństwo konstrukcji

\footnotetext{
${ }^{1}$ Autor do korespondencji/corresponding author: Czesław Miedziałowski, Politechnika Białostocka, ul. Wiejska 45A, 15-351 Białystok, 797995940, c.miedzialowski@ pb.edu.pl

${ }^{2}$ Michał Baszeń, Politechnika Białostocka, jw., 797995942, m.baszen@pb.edu.pl

${ }^{3}$ Marta Kosior-Kazberuk, Politechnika Białostocka, jw., 797995935, m.kosior@pb.edu.pl

4 Anna Żakowicz, Politechnika Białostocka, jw., 797995946, a.zakowicz@pb.edu.pl

5 Tadeusz Chyży, Politechnika Białostocka, jw., 797995941, t_chyzy@interia.pl

${ }^{6}$ Damian Siwik, Politechnika Białostocka, jw., 794684965, kiwis1@ poczta.fm
} 


\section{Wstęp}

W drugiej połowie XX wieku znaczącą część wielorodzinnych budynków mieszkalnych zrealizowano $\mathrm{w}$ uprzemysłowionych systemach prefabrykowanych, wielkoblokowych i wielkopłytowych, jak systemy Żerań, Wk, OWT $\mathrm{i}$ innych [2].

W pobliżu Białegostoku stoi nieukończona konstrukcja budynku w systemie OWT, na terenie budowanego wcześniej zakładu mleczarskiego. Wznoszenie budynku rozpoczęto w styczniu 1989 r. Planowano obiekt pięciokondygnacyjny z podpiwniczeniem. Do zamknięcia stanu surowego zabrakło konstrukcji ostatniego poziomu tj. stropodachu, co widać na rysunku 1.

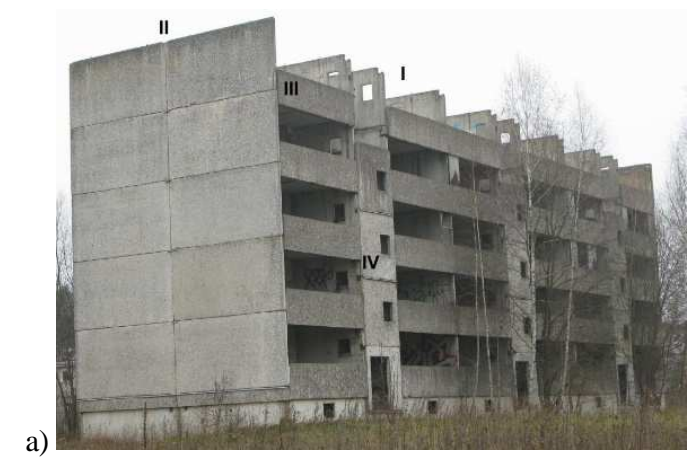

b)

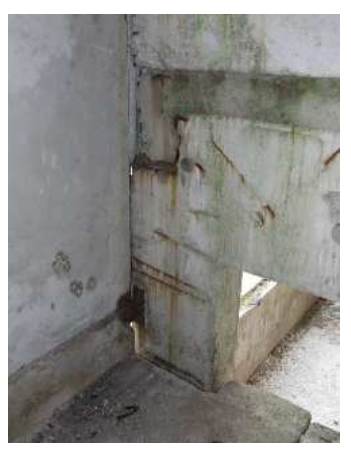

Rys. 1. Analizowana konstrukcja budynku: a) widok budynku, b) szczegół konstrukcji klatki schodowej

Fig. 1. Analyzed building structure: a) view of building, b) detail of a staircase

Po zaniechaniu dalszej realizacji budynku, obiekt pozostał nieukończony i w stanie otwartym do chwili obecnej. Jest więc możliwość przeanalizowania jakości zrealizowanych robót, jakości dostarczonych prefabrykatów, degradacji konstrukcji w czasie. Wybrane przykłady zostaną podane w opracowaniu. Ponadto $\mathrm{w}$ pracy zostanie przedstawiona propozycja efektywnego modelu do analizy statycznej konstrukcji tego typu budynków.

\section{Jakość zrealizowanych robót}

Obiekt został wzniesiony w technologii OWT-67N. Dokonano przeglądu i inwentaryzacji niektórych odkrytych węzłów wg lokalizacji jak na rysunku 1 (I, II, III, IV).

W węzłach ścian obserwuje się nierówności i odchyłki geometryczne elementów konstrukcyjnych i montażu oraz brak lub zbyt krótkie spoiny. Na rysunku 2 pokazano widok węzła typu II tj. ściana szczytowa - wewnętrzna ściana podłużna oraz jego geometrię w stanie istniejącym. Według wymagań katalogowych [7] minimalne spoiny powinny wynosić 4x80mm. 
a)

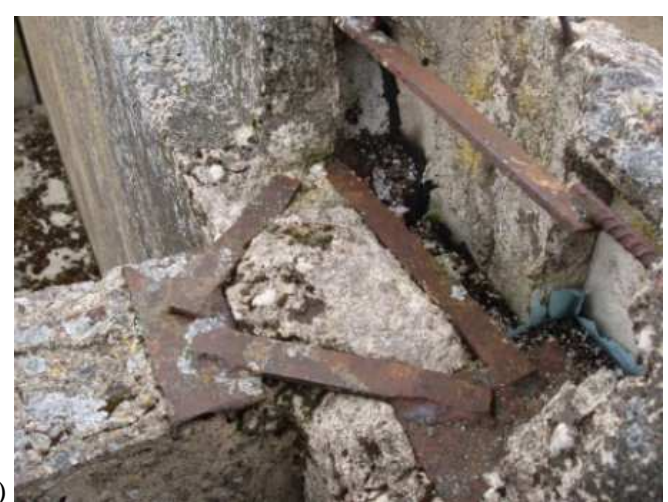

b)

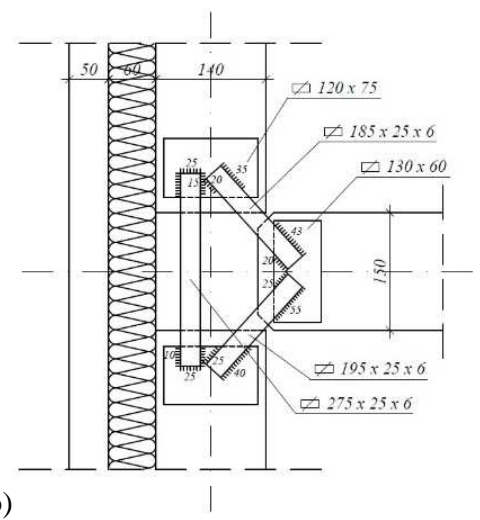

Rys. 2. Widok węzła łączącego ścianę szczytową ze ścianą podłużną (a) oraz geometria połączenia wg stanu istniejącego (b)

Fig. 2. View of the joint connecting the gable wall with longitudinal one (a) and the geometry of the joint according to the existing state (b)

Na rysunku 3a pokazano widok, a na rysunku 3b geometrię wg katalogu [7], połączenia belkościany (tzw. zetki ,Zs”) ze ścianą poprzeczną klatki schodowej.

a)

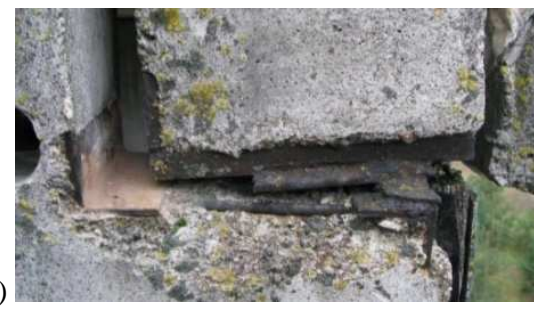

b)

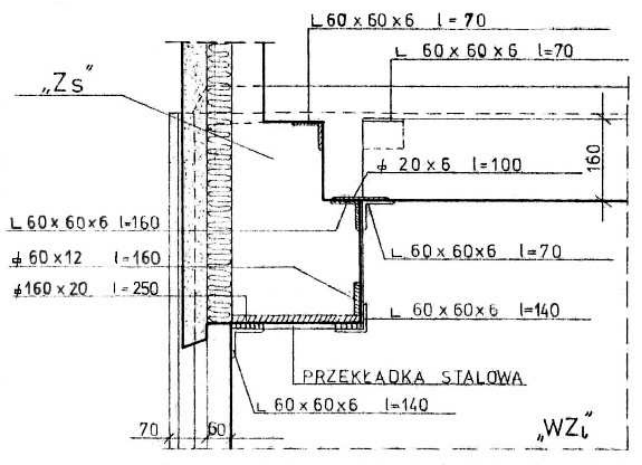

Rys. 3. Widok węzła łączącego zewnętrzną belkościanę ze ścianą poprzeczną przy klatce schodowej (a) oraz geometria wg wymagań katalogowych (b)

Fig. 3. View of joint connecting the external wall with transverse wall at staircases (a) and the geometry according to the catalogue requirements (b)

Przedstawione powyżej wady montażowe i ich lokalizacja mogą stanowić zagrożenie bezpieczeństwa konstrukcji. 


\section{Stan betonu i stali w konstrukcji}

Przyczyn stanu i uszkodzeń elementów konstrukcyjnych należy szukać w niewłaściwym wykonaniu elementów prefabrykowanych, wadliwym montażu i prawdopodobnie zbytniej pobłażliwości kontroli technicznej w czasie wykonawstwa. Nie można wykluczyć wbudowania uszkodzonych wadliwych połączeń elementów, a także niedokładnego ich usytuowania. Ponadto nieosłonięta konstrukcja budynku OWT była narażona na stałe oddziaływanie czynników agresywnych w stosunku do betonu i żelbetu, takich jak dwutlenek węgla $\mathrm{z}$ atmosfery, wody opadowe, a w okresie zimowym dodatkowo, cykliczne zwilżanie, zamrażanie i rozmrażanie [9], [11]. Bezpośrednie oddziaływanie czynników atmosferycznych uwidoczniło słabe punkty obiektu, w których proces degradacji przebiegał szczególnie intensywnie.

Oględziny płyt ściennych i stropowych wykazały zróżnicowaną jakość betonu w elementach prefabrykowanych. Powierzchnie w dobrym stanie sąsiadują z miejscami, gdzie widoczne jest intensywne łuszczenie się i odpryski betonu. Złuszczanie się powierzchniowej warstwy w postaci płatów zaprawy lub zaczynu grubości kilku milimetrów mogło być spowodowane kumulacją błędów technologicznych (błędy w składzie betonu, rozwarstwianie mieszanki betonowej po ułożeniu) i specyficznych warunków ekspozycji konstrukcji. Oszacowana grubość warstwy skarbonatyzowanej, która utraciła właściwości ochronne w stosunku do stali zbrojeniowej, wahała się od 2 do $4,5 \mathrm{~cm}$, obejmując swoim zasięgiem zbrojenie.

Odspojoną otulinę i skorodowane zbrojenie stwierdzono zarówno w płytach stropowych, jak i w elementach pionowych. W wielu płytach ściennych i stropowych otulina prętów zbrojeniowych była tak cienka (grubość mniejsza niż $10 \mathrm{~mm}$ ), że widoczna jest siatka skorodowanych prętów zbrojeniowych, rysunek 4a. Ponadto, obserwowano pęknięcia elementów ściennych oraz wyraźne zarysowania złączy pionowych.

Stwierdzono zaawansowaną degradację krawędzi płyt stropowych w miejscach połączeń. Wypełnienie styków wykonano niestarannie, a zastosowany beton jest porowaty, z rakami, nieszczelny itp. Zbrojenie krawędziowe płyt stropowych w wielu miejscach odsłonięte i skorodowane na całej długości.

Istotną wadą montażu okazało się nieprawidłowe wykonanie złączy i połączeń stalowych łączących elementy prefabrykowane. Ponadto, niestarannie wykonana, porowata warstwa zaprawy niskiej jakości nie chroni elementów stalowych przed korozją. Część połączeń stalowych, które na ostatniej niezakrytej kondygnacji pozostały odsłonięte przez cały okres od wzniesienia obiektu, jest skorodowana, miejscami dość głęboko.

Zawilgocenie, biologiczny charakter środowiska wodnego oraz dostęp promieniowania słonecznego stworzyły dogodne warunki do rozwoju na powierzchni betonu mchów i porostów, co widać na rysunku 4b. W przypadku niższych kondygnacji inwazja biologiczna nie jest tak znacząca. Brak bezpo- 
średniego dostępu wód opadowych do ścian i stropów niższych kondygnacji, nie pozwalał na tak samo intensywny rozwój procesów korozyjnych i destrukcyjnych, jak w przypadku dwóch najwyższych kondygnacji.

a)
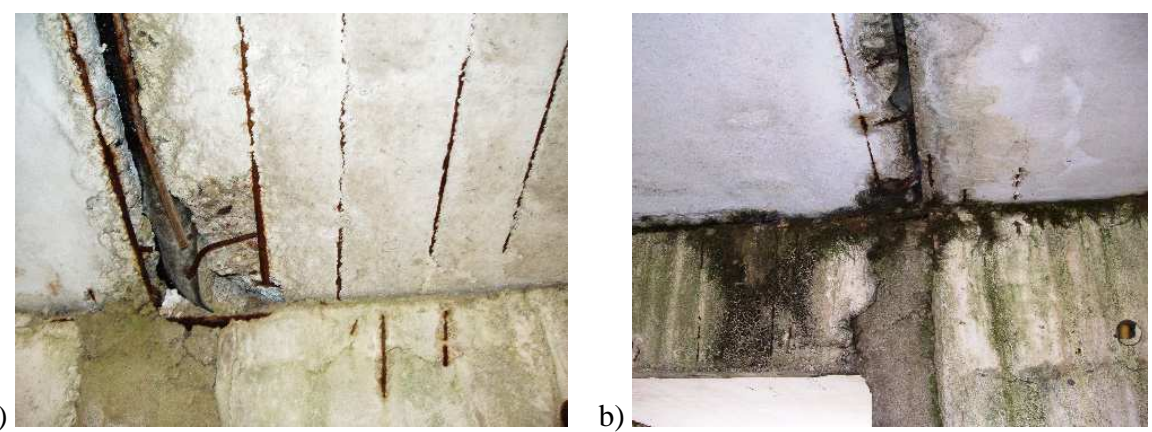

Rys. 4. Skorodowane zbrojenie w płytach o zbyt cienkiej otulinie (a), efekty zawilgocenia w węzłach (b)

Fig. 4. Corroded reinforcement in slabs with too thin concrete cover (a), the effects of moisture in the joints (b)

Podane powyżej wady i degradacja konstrukcji w analizowanym budynku wskazują na konieczność diagnostyki i modernizacji tego typu budynków [3], [6], [8], [11]. Powinien być uwzględniony ich rzeczywisty stan, aktualne obciążenia i oddziaływania oraz współczesne modele obliczeniowe w schematach trójwymiarowych.

\section{Propozycja sposobu analizy}

Sposób analizy bazuje na dotychczas opracowanych dużych elementach skończonych i sposobach ich implementacji w analizach [1], [4], [5]. W budowie w/w elementów wykorzystano pasmową strukturę budynków (ściany, stropy) i sformułowano je na bazie belek krępych lub izoparametrycznych funkcji kształtu. Otrzymano w ten sposób duże elementy skończone opisujące elementy konstrukcyjne wysokości kondygnacji, szerokości traktów i uwzględniające stany tarczowe oraz płytowe wg rysunku 5.

Agregację poszczególnych elementów dokonuje się wprowadzając numerację i globalny układ współrzędnych, wg schematu:

$$
\begin{aligned}
& \mathbf{K}=\sum_{r e} \sum_{e} \mathbf{K}_{\mathrm{e}} \\
& \mathbf{P}=\sum_{r e} \sum_{e} \mathbf{P}_{\mathrm{w}}
\end{aligned}
$$

gdzie: re - rodzaje elementów (ściany, stropy, złącza, grunt),

e - kolejne elementy danego rodzaju, 
$\mathbf{K}_{\mathrm{e}}$ - macierz sztywności elementów,

$\mathbf{P}_{\mathrm{w}}-$ obciążenia zewnętrzne.

Po wprowadzeniu warunków brzegowych, otrzymuje się ostateczny macierzowy układ równań modelu dyskretnego:

$$
\mathbf{K d}=\mathbf{P}
$$

gdzie: $\mathbf{K}$ - globalna macierz sztywności układu,

d - globalny wektor przemieszczeń,

$\mathbf{P}$ - globalny wektor obciążeń.

a)
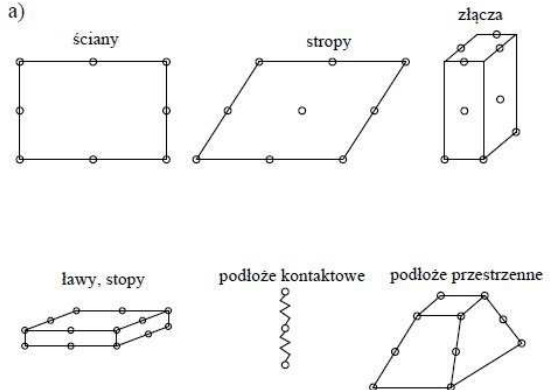

elementy liniowe wzmocnienia

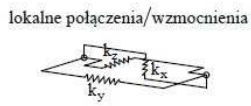

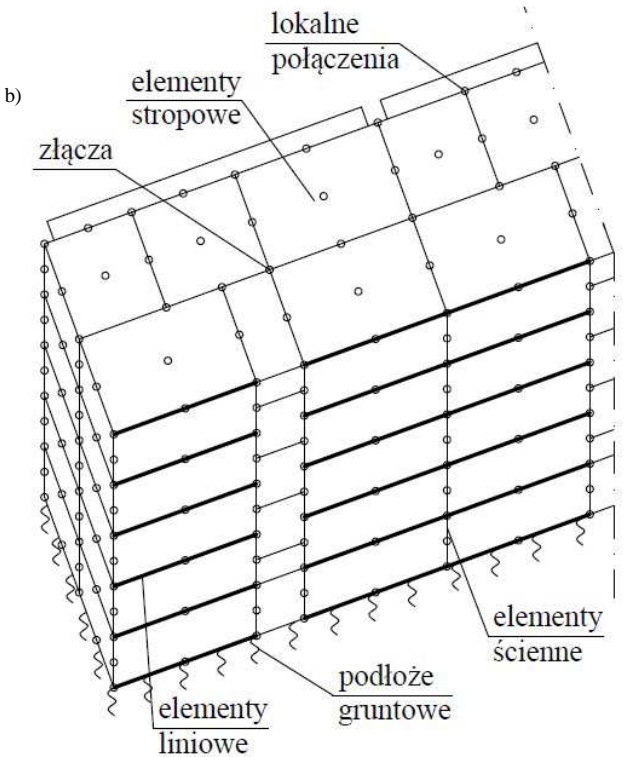

Rys. 5. Schemat modelu obliczeniowego: a) typy elementów skończonych, b) przykład dyskretyzacji konstrukcji elementami skończonymi

Fig. 5. Scheme of the calculation model: a) the types of finite elements, b) an example of discretization of structure using finite elements

W rozwinięciu ze względu na rodzaj stopni swobody dla podłoża gruntowego typu kontaktowego otrzymuje się następujący schemat układu równań:

$$
\left[\begin{array}{lc}
\mathbf{K}_{11} & \mathbf{K}_{12} \\
\mathbf{K}_{21} & \mathbf{K}_{22}+\mathbf{K}^{\mathrm{f}}
\end{array}\right]\left\{\begin{array}{l}
\mathbf{d}_{\mathrm{k}} \\
\mathbf{d}_{\mathrm{f}}
\end{array}\right\}=\left\{\begin{array}{l}
\mathbf{P}_{\mathrm{k}} \\
\mathbf{P}_{\mathrm{f}}
\end{array}\right\}
$$

gdzie: $\mathrm{k}$ - stopnie swobody w konstrukcji,

$\mathrm{f}$ - stopnie swobody na styku konstrukcji z podłożem gruntowym,

$\mathrm{K}^{\mathrm{f}}$ - macierz sztywności podłoża gruntowego. 
Dla budynków podobnych do analizowanego, używając do dyskretyzacji przedstawione elementy skończone, ich liczba będzie w granicach 300, tj. ok. 1200 węzłów co generuje kilka tysięcy niewiadomych.

\section{Podsumowanie}

1. W analizowanym budynku stwierdzono niedokładność i znaczne wady montażowe, które mogą stanowić zagrożenie bezpieczeństwa konstrukcji. Wymaga to udokładnionej analizy statyczno-wytrzymałościowej.

2. Połączenie ściany szczytowej ze ścianą podłużną ma zbyt małe spoiny w łącznikach stalowych. Występują ponadto odchyłki geometryczne i nierówności w płaszczyznach.

3. Stwierdzono bardzo niestaranne i z brakami konstrukcyjnymi połączenia belkościan ze ścianami poprzecznymi, szczególnie od strony klatek schodowych (nierówności, podkładki, brak spoin).

4. Elementy prefabrykowane mają widoczne odchyłki wymiarowe, zbyt cienką otulinę zbrojenia oraz słabe zabezpieczenie antykorozyjne połączeń stalowych.

5. Przedstawiony sposób obliczeń umożliwia ujęcie pracy przestrzennej konstrukcji wraz z występującymi defektami oraz wzmocnieniami przy stosunkowo niedużej liczbie niewiadomych.

\section{Literatura}

[1] Chyży T.: Metoda analizy macierzowej statycznych i dynamicznych modeli budynków tarczowych z uwzględnieniem problemów nieliniowych. Rozprawa doktorska, Politechnika Białostocka, Białystok 1992.

[2] Dzierżewicz Z., Starosolski W.: Systemy budownictwa wielkopłytowego w Polsce w latach 1970-1985, Przegląd rozwiązań materiałowych, technologicznych i konstrukcyjnych, Wydawnictwo Oficyna Wolters Kluwer business, Warszawa 2010.

[3] Ligęza W.: Aspekty rewitalizacji budynków wielkopłytowych. Zakres zagadnień technicznych, II Konferencja Naukowo-Techniczna „Nowoczesne materiały, techniki i technologie we współczesnym budownictwie”, Kraków 21-23 października 2015, s. 151-172.

[4] Miedziałowski Cz.: Dyskretny model złożonych konstrukcji ścianowych budynków uwzględniający współpracę podłoża gruntowego, Rozprawy Naukowe $\mathrm{Nr} 24$, Wydawnictwa Politechniki Białostockiej, Białystok 1994.

[5] Miedziałowski Cz., Siwik. D.: Static analysis of building structures with regard to their implementation in stages, Engineering Structures, nr 102, 2015, s. 249-257.

[6] Podhorecki A., Sobczak-Piąstka J.: O potrzebie diagnozowania i rewitalizacji budynków wielkopłytowych, XIII Konferencja Naukowo-Techniczna „Warsztat pracy rzeczoznawcy budowlanego”, Kielce-Cedzyna 21-23 maja 2014, s. 400-419. 
[7] Praca zbiorowa: Katalog - Projekt konstrukcyjny: detale konstrukcyjne węzłów kondygnacji powtarzalnych, elementów dachu i elewacji, „Miastoprojekt - Białystok", 1987.

[8] Runkiewicz L. i in.: Diagnostyka i modernizacja budynków wielkopłytowych, XIII Konferencja Naukowo-Techniczna „Warsztat pracy rzeczoznawcy budowlanego”, Kielce-Cedzyna 21-23 maja 2014, s. 420-443.

[9] Ściślewski Z.: Trwałość elementów wielkiej płyty. Materiały Budowlane, nr 11/2004, s. 3-4.

[10] Tang S.W., Yao Y., Andrade C., Li Z.J.: Recent durability studies on concrete structure, Cement and Concrete Research, 78 (2015) s. 143-154.

[11]Zieliński J.W.: O możliwościach modernizacji konstrukcji budynków wielkopłytowych, Inżynieria i Budownictwo nr 3/2000, s.133-136.

Badania zostały zrealizowane w ramach pracy S/WBiIŚ/5/2013 i finansowane ze środków na nauke MNiSW.

\title{
CONDITION OF UNCOMPLETED STRUCTURE OF PANEL BUILDING 25 YEARS AFTER CONSTRUCTION AND PROPOSED METHOD OF STATIC ANALYSIS
}

\begin{abstract}
S u m m a r y
The paper concerns the technical state of uncompleted structure of panel building (OWT system) examined 25 years after erection. The stage of construction process and the quality of performed works were presented and the joints' geometry and their reference to the requirements of the system catalog were analyzed. The condition of joints of the gable walls to the longitudinal wall as well as the joints of external walls to transverse ones were presented. The data concerning the condition of the concrete in structural elements and the condition of steel in joints were given. The places especially degraded and threatened by corrosion were indicated. The embedded prefabricated elements with defective geometry and improper material properties, and incorrect assembly of structural elements were found. The effective method for static analysis of the building in a three-dimensional model, including the subsoil, defective assembly and additional impacts on the structure was presented. In conclusion, the major defects identified in the panel building, which could threaten the safety of structure, were given.
\end{abstract}

Keywords: panel buildings, prefabricated elements, joints, safety of structure

Przestano do redakcji: 07.06.2016 $r$.

Przyjęto do druku: 30.06.2016 r.

DOI: $10.7862 / \mathrm{rb} .2016 .3$ 